\title{
Vulnerability Continues for Syrian Refugee Children
}

\section{Ozdogan $\mathrm{T}^{1 *}$ and Ozdogan $\mathrm{E}^{2}$}

${ }^{1}$ Department of Medical History and Ethics, Istanbul University School of Medicine, Turkey ${ }^{2}$ Koc University School of Medicine, Turkey

*Corresponding author: Tutku Ozdogan, Department of Medical History and Ethics, Istanbul University School of Medicine, Turkey, Tel: 5323254278; Email: tutkuozdogan@yahoo.com

\section{Case Report}

Volume 3 Issue 3

Received Date: August 10, 2020

Published Date: September 09, 2020

DOI: $10.23880 /$ abca-16000132

\section{Abstract}

Turkey hosts the largest number of Syrian refugees. The birth rate of Syrian newborns in Turkey increases day by day and they also need intensive care and other therapies. Here we report the case of a Syrian infant who had permanent vision loss after a series of events that reflects the cultural and language barriers as well as the social injustice faced by the refugees.

Keywords: Neonatal Intensive Care; Retinopathy of Prematurity; Turkish National Pediatric Society

\section{Introduction}

A civil war broke out in Syria in 2011 and millions of Syrians have escaped across borders. Today, Turkey hosts the largest number of Syrian refugees. The number of Syrian refugees in Turkey has reached about 3.7 million people in July 2020. The percentage of children up to age 4years is $\% 14$ of the total population of refugees. The $\% 1.75$ of refugees live in refugee camps and \%98.75 live in cities [1].

The birth rate of Syrian newborns in Turkey increases day by day and most of the Syrian refugees do not have adequate antenatal follow-up and the exact number is not known because of the language barrier and consequent communication problems. According to a study by Celik IH, et al. [2] the neonatal intensive care (NICU) admission rates and mortality rates of refugee and Turkish infants were similar (0.8\% vs. $0.4 \%$ )[2]. However, the rate of developing perinatal asphyxia was significantly higher among Syrian infants. Here we report the case of a Syrian infant who had permanent vision loss after a series of events that reflects the cultural and language barriers as well as the social injustice faced by the refugees.

\section{Case Report}

A 34 week born preterm baby boy whose parents were refugees from Syria was treated in a private hospital NICU for 45 days. At discharge, the baby was approximately 6 weeks old, which is the recommended age for screening for retinopathy of prematurity (ROP) (the most common cause of blindness in childhood). However, the screening was not done and the parents were not adequately informed prior to the discharge. He was admitted to a public teaching hospital due to pneumonia a few days later. In this admission, he was treated for the pneumonia and discharged without further recommendations. He was not screened for ROP in this hospital either, although that hospital had able ophthalmologists. After a while, he was admitted to the same hospital for pneumonia again. During this admission, the baby was seen by one of the more experienced neonatologists who did not see the baby in the prior admission. This neonatologist did ask for an ophthalmology consultation and the baby was 70 days (10weeks) old at this point. Due to delays in adequate screening he was diagnosed with Grade 5 ROP, which is associated with permanent vision loss. Due to the language barriers and the unavailability of a translator, this diagnosis was not effectively communicated to the parents. The difficulty their child will have growing up, the need for physical rehabilitation and the irreversibility of the vision loss were not properly conveyed to the parents. Furthermore, the healthcare personnel insisted that the fault lied with the parents as they did not bring the baby to ophthalmology clinic to his appointment, although ROP examination was available at inpatient clinics. 


\section{Discussion}

In a recent paper by Özmert EN, et al. [3] the refugee problem is well described from the point of health, education and psychosocial needs of Syrian children in Turkey [3]. If the refugees apply for immigration status the healthcare coverage of most of the costs is provided to refugees in Turkey [2]. In our case, NICU and other treatment costs were paid by the government and the problem was oriented from mostly communication difficulties. However, when we look at in a wider ethical view, medical negligence was the main issue of moral concern.

In a recent multicenter paper from Turkey, the criteria for ROP screening in Turkey include "infants with a GA $\leq 34$ weeks or a $\mathrm{BW}<1700 \mathrm{~g}$ ". In this paper the preterm infants born to Syrian refugees were also included. There were no differences in any ROP and severe ROP development between preterm infants of refugees and Turkish infants in this study [4]. However, it should be noted that this study was a prospective cohort study, which might have introduced Hawthorne bias, i.e. increased the rates of performing adequate screening because of the knowledge of being included in a study. As a result, it is difficult to generalize these findings.

A systematic review by Heslehurst N, et al. [5] showed that perinatal health care outcomes of refugees affected negatively by language barriers, insensitive communication style and cultural differences between pregnant women and health professionals. In this review especially the rise in maternal mental health disorders were emphasized [5]. Being under the same circumstances, Turkish National Pediatric Society (TNPS) with the help of media aimed to increase the social and international awareness about these children and emphasized the tagline "everything starts with love" [3].
The Turkish government is providing medical support to refugees for a long time. Yet, it is clear that the communication problems cause more harm than expected to children. We know that health care personnel should always follow the "first do no harm" principle.

\section{Conclusion}

In conclusion, both the Turkish healthcare professionals and government need to address not only the financial but also the psychosocial barriers to adequate care. Otherwise, the cost to this vulnerable population will be significant and irreversible.

\section{References}

1. (2020) Number of Syrians in Turkey in August 2020: Turkiye’Deki Suriyeli Sayisi. Multeciler Dernegi.

2. CelikIH,ArslanZ, Ulubas ID, Tapısız OL, Mollamahmutoğlu L, et al. (2019) Neonatal outcomes in Syrian and other refugees treated in a tertiary hospital in Turkey. Turk J Med Sci 49(3): 815-820.

3. Ozmert EN, Derman O, Bideci A, Okumuş N, Boduroğlu K, et al. (2019) Syrian Children in Turkey: A Model of Action for National Pediatric Societies. Pediatrics 143(2): e20180539.

4. Bas AY, Demirel N, Koc E, Isik DU, Hirfanoglu IM, et al. (2018) Incidence, risk factors and severity of retinopathy of prematurity in Turkey (TR-ROP study): a prospective, multicenter study in 69 neonatal intensive care units. $\mathrm{Br}$ J Ophthalmol 102(12): 1711-1716.

5. Heslehurst N, Brown H, Pemu A, Coleman H, Rankin J (2018) Perinatal health outcomes and care among asylum seekers and refugees: a systematic review of systematic reviews. BMC Medicine 16(89): 1-25. 